\title{
Use of Air-deployed Drogued Drifting Buoys for Oil Spill Tracking
}

\author{
Neha Sharma, Peter Brickley, George Owen, and Patrice Coholan \\ Horizon Marine, Inc. \\ 15 Creek Road \\ Marion, MA 02738 USA
}

\begin{abstract}
The magnitude of the recent Gulf of Mexico oil spill resulting from the Macondo oil well blowout, catastrophic explosion, and subsequent sinking of the Deepwater Horizon semi-submersible offshore drilling rig is unprecedented. The complex oceanographic and environmental character of the spill location and the application of vast quantities of chemical dispersants combined to create greater challenges for those tasked with mapping the areal extent of the oil and the advective pathways by which the oil would eventually reach both the nearby shore or become entrained into the vigorous offshore currents of the deepwater Gulf. The action of the chemical dispersants combined with surface winds and wave action resulted in high loads of oil particles throughout the mixed layer and extensive surface slicks. In addition, the oil disaggregated into hundreds of small patches instead of remaining pooled on the surface. Under these unexpected conditions, the tracking and forecasting of the spill presents a challenge.
\end{abstract}

Horizon Marine, Inc., an operational oceanographic monitoring and forecasting company, has been actively involved in the oil spill response efforts and supported the current monitoring program near the Deepwater Horizon incident site. One method employed to delineate the initial area of the oil patch and track its expanding perimeter was the use of air-deployable drifting buoys (Far Horizon Drifters). These buoys are equipped with GPS receivers, transmit new positions hourly via satellite, and were nominally drogued at $5 \mathrm{~m}$ and $50 \mathrm{~m}$ to provide coverage of the upper water column. Using these observations, we describe several major transport pathways resulting from physical mechanisms operating over different scales. The entrainment of several buoys into the Loop Current and associated frontal eddies provided early indication of potential pathways taken by both the visible surface and invisible subsurface oil.

\section{INTRODUCTION}

One of the most disturbing repercussions of offshore drilling in the history of the oil and gas industry has been the potential for oil spills and the resulting ecological devastation. Although not the first, the Deepwater Horizon oil spill has proved to be the largest and most catastrophic in U.S. waters. Previous experience from fateful oil spills, like the Ixtoc I and Exxon Valdez spills, provided little insight on the extent of the latest Deepwater Horizon spill. The semi-submersible offshore drilling rig was operating in $1500 \mathrm{~m}$ of water when it experienced a fatal explosion on 20 April 2010. The explosion resulted in the prolonged expulsion of oil from the sea floor and the broken riser before the well was finally capped on 15 July. Estimates of the volume of oil lost from the well range from 94 to 184 million gallons.

Due to the limited effectiveness of mechanical recovery processes such as skimming, booming, and in situ burning dispersants were used on the oil spill to mitigate harmful effects on sensitive nearshore and coastal habitats and wetlands [1-7]. Oil spill dispersants are chemicals applied directly to the oil in order to separate the thick, cohesive oil slick on the surface into tiny droplets (mixture of oil and dispersants) of significantly reduced size and volume that can then mix into the water column. This process aids bacterial degradation of the oil. Dispersants were also injected at the very source of the oil expulsion; i.e., at the sea floor. By the end of May, more than 950,000 gallons of dispersant had been used on the oil spill.

Traditional methods used to track oil include remote sensing, over-flight mapping, use of oil spill models, and oil spill drifters. The use of these methods in conjunction with active monitoring of ocean currents is critical for describing and predicting the three-dimensional pathways and transport of liquid oil, tar balls, or oil dispersed in the mixed layer. For monitoring oil in the far field, it is often the combination of remote sensing products and in-situ drifting buoys that are both readily available or deployable. These are, therefore, valuable tools for responding rapidly to the serious nature of these spills. As a general rule, satellite-tracked GPSpositioned buoys are well suited for tracking the position of an oil slick [8]. A typical oil-tracking surface drifter in use by many agencies is the Self-Locating Datum Marker Buoy (SLDMB). These are "Davis-style" buoys designed to drift with the surface flow and, thus, are an adequate tracer for surface oil movement. These instruments play a key role in providing estimates of the oil trajectory due to limitations of over-flight mapping (cloud coverage, bad weather conditions, etc.) and oil spill modeling (limited ground truthing without drifters). Studies of the effectiveness of drifters in oil spill tracking attribute high confidence in their use for the purpose [8], [9], \& [10]. In general, these buoys are found to move on the ocean surface like consolidated oil slicks under light to moderate wind conditions, and their trajectories are compared statistically with model outputs [9]. Several varieties of Davis-style drifters are utilized by NOAA, the Coast Guard, and the Naval Oceanographic Office.

With the extensive mixing of oil-dispersant droplets into the water column, the prevailing ocean currents in the mixed layer and regional circulation will likely become a significant influence on the spread of the oil spill. Under these conditions, several other types of satellite-tracked drifters can be used. These buoys are typically drogued to drift with the current at a 
specific depth to capture the mean current flow in the upper water column and are designed to have a minimal response to direct wind forcing on the surface float. Two such drifters are the NOAA GTS buoy, and the Far Horizon Drifter (FHD).

Monitoring of oil dispersion and transport over the Northern Gulf of Mexico (NGOM) slope represents a significant challenge in this dynamic region. The circulation in the northern and eastern Gulf of Mexico (GOM) is complex, comprised of currents which, near the shelf, are driven by wind and buoyancy forcing from large volumes of freshwater and, in the open ocean, by wind stress, the Loop Current, and energetic eddies. Over the slope is a similarly dynamic regime that consists at times of many small eddies, both cyclonic and anticyclonic [11]. The main features of Gulf of Mexico circulation can be visualized in Fig. 1 from the collected trajectories of drifters in the area following the Deepwater Horizon accident.

In response to the Deepwater Horizon incident, Horizon Marine deployed numerous drifters (many are shown in Fig. 1) to augment and extend the network of drifters used to help forecast oil movement for oil spill responders. In this paper, we describe several episodes where the use of Lagrangian drifters provided critical information about the developing transport pathways for oil advection. The episodes reflected the multiplicity of oil transport pathways and the varying role of physical mechanisms that influenced the oil transport, including along-shelf transport by local wind forcing on the shelf and entrainment and dispersion by the oceanic mesoscale eddy field.

\section{DRIFTER TYPES}

\section{A. Far Horizon Drifters}

The Far Horizon Drifter (FHD) (Fig. 2) is a low-cost, airdeployable drifting buoy that was was deployed in 1985 in the Gulf of Mexico. Over 2560 satellite-tracked drifters have been air deployed from a fixed wing aircraft into the Gulf of Mexico over the past 26 years as part of a Loop Current monitoring program. The cylindrical buoy hull measures 96.5 $\mathrm{cm}$ by $12.4 \mathrm{~cm}$. The parachute has an effective drag area of $1.28 \mathrm{~m}^{2}$ and is connected to the buoy with a $45 \mathrm{~m}$ nylon tether. . The ratio of drogue cross-sectional area to the cross-sectional area of the surface float is $\sim 60: 1$. Each FHD is equipped with a GPS receiver, allowing for position retrieval every hour. Battery lifetime ranges from 120-180 days. These buoys have the same design as the regular FHDs (Fig.2) but use a $4.5 \mathrm{~m}$ drogue instead of $45 \mathrm{~m}$. Although studies have shown a "holey sock" drogue is more efficient than a parachute drogue at anchoring the drifter in a water parcel [12], the parachuteshaped drogue design gains significant practical advantages through its dual use as an air-deployment system.

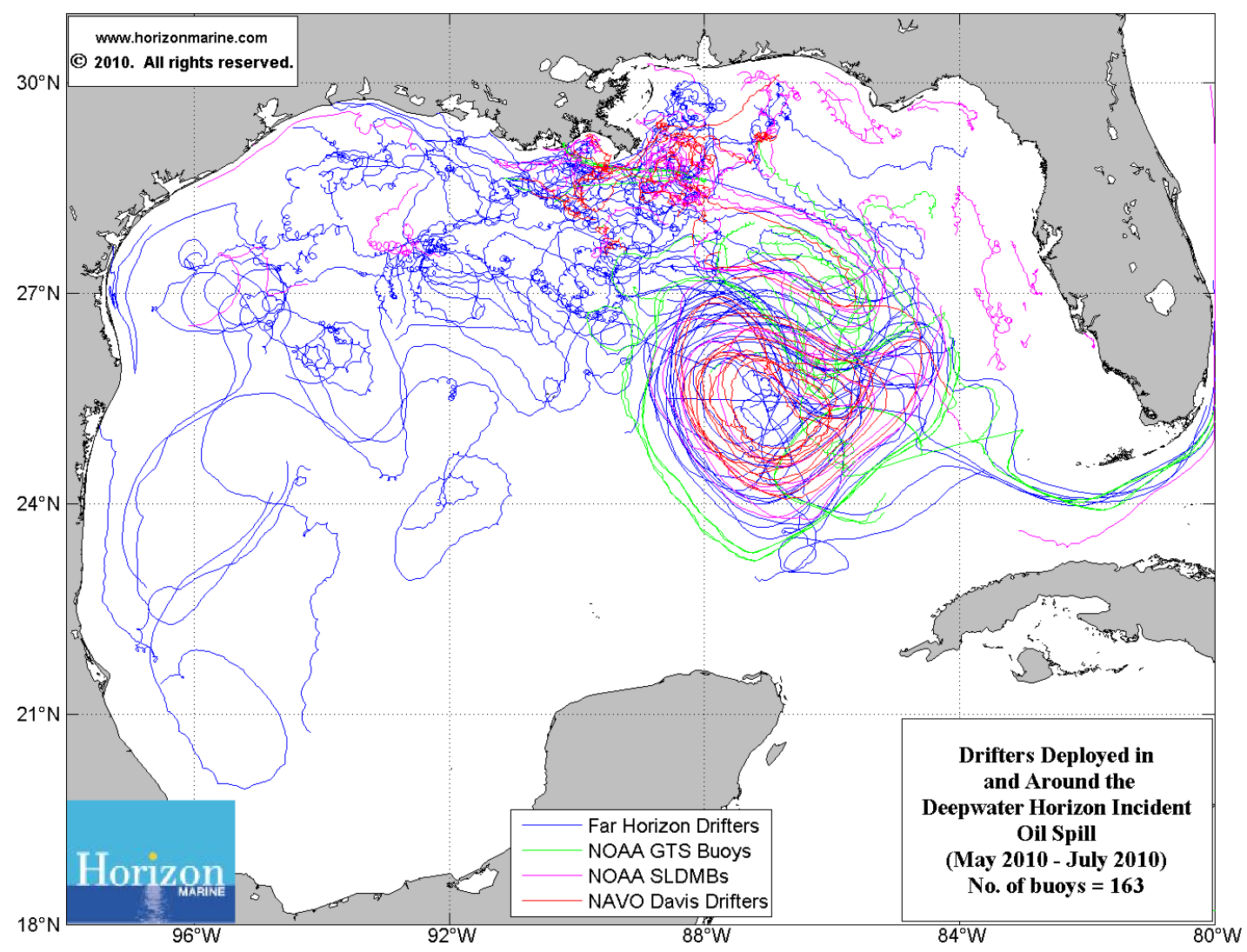

Figure 1. Drifter trajectories through the Gulf of Mexico between 1 May 2010 and 20 July 2010. 


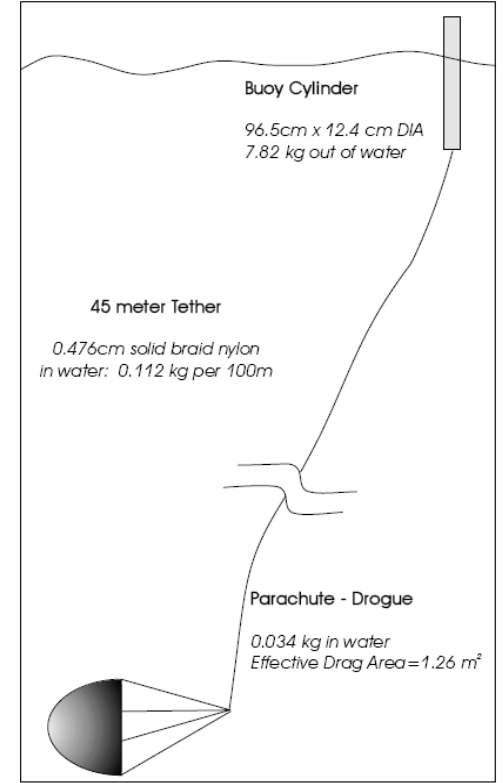

Figure 2. Far Horizon Drifter (FHD) design and dimensions.

\section{B. SLDMB or Davis Drifters}

The SLDMB is based on the Davis-style drifter design which attempts to minimize the effects of wind and surface waves. The drogue consists of four orthogonal fabric vanes $0.5 \mathrm{~m}$ wide and $0.7 \mathrm{~m}$ long; the entire float extends to $1 \mathrm{~m}$ depth. These are supported by PVC arms at the top and bottom which extend from a cylindrical hull that contains the electronic equipment. Small floats are attached to the end of each upper arm in order to maintain buoyancy, and a small antenna projects above the SLDMB. Electronics consist of a GPS receiver, electronic transmitter, and sufficient batteries to provide continuous data collection for a period of two weeks to one month.

\section{MEASUREMENT PROgRAM AND DATA ANALYSIS}

\section{A. Initial Oil Patch Spread}

Early reports on 23 April indicated that the oil spill had already formed a surface slick $1.6 \mathrm{~km}$ wide by $8 \mathrm{~km}$ long. By 25 April aerial surveys reported sheen spreading over a surface area of $32 \mathrm{~km}^{2}$ containing emulsified crude oil [13]. Within two days, the edge of this slick approached within $40 \mathrm{~km}$ of the coast of Louisiana, implying a rapid spread and advection of surface oil. Oil distribution maps derived from satellite imagery available from NOAA NESDIS (www.ssd.noaa.gov/PS/MPS/deepwater.html) provided an independent synoptic record of the oil's spread over the first two weeks of the spill. These polygonal maps were derived from the visible boundary of surface oil in satellite sun glint imagery (Fig. 3). These maps were subject to known biases due to the strong dependency of sun glint on the satellite's view geometry relative to the oil and failure to discriminate thick oil layers from thin ones. Nevertheless, we calculated the geometric area of the patches to arrive at a time series of oil-covered area. This clearly shows a roughly linear increase over a 10-day span from $<4000 \mathrm{~km}^{2}$ on 26 April to $>13000 \mathrm{~km}^{2}$ on 05 May.

\section{B. Drifter Dispersion Rates}

On 04 May, Horizon Marine deployed 10 FHDs into the oil patch with guidance from NOAA's Office of Response and Restoration (NOAA ORR). Six of these drifters were modified with $4.5 \mathrm{~m}$ tethers to better track oil dispersed into the mixed layer and were deployed in a cluster around the northeastern portion of the oil patch (Fig 4a). Here we examine the dispersion rates experienced by FHDs deployed into the northeast portion of the oil spill. The location of the spill boundary was estimated from aircraft visual observations and satellite images available on the morning of 04 May.
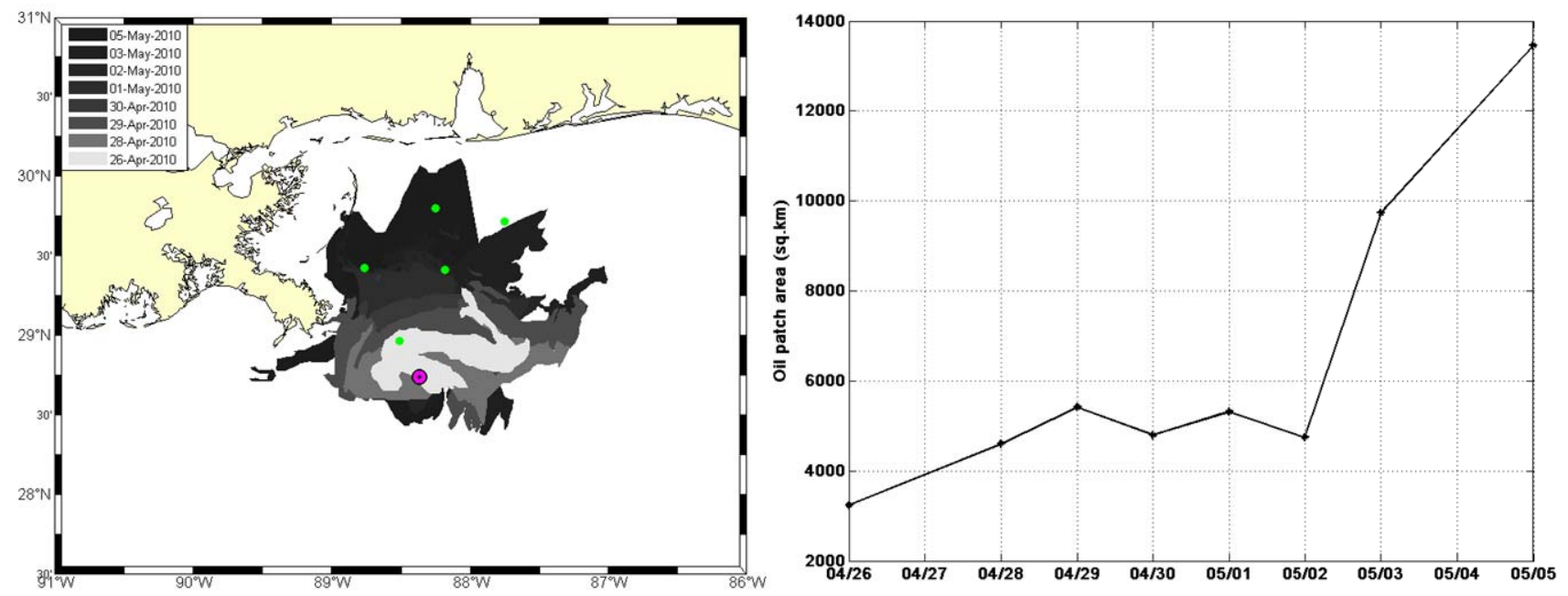

Figure 3. NESDIS Sun glint derived images of the oil trajectory between 26 April and 5 May with initial FHD (\#s 2528-2533) deployment locations (green dots) (left panel) and a time series of oil patch area during the same time period (right panel). 
The data were first treated to remove bad positions from spurious GPS fixes and interpolated to a common time base of two hour intervals. We applied the method for estimating dispersion from clustered drifter deployments outlined in [14]. The initial cluster covered a polygonal area of $\sim 8000$ $\mathrm{km}^{2}$ northeast of the Mississippi Delta. To quantify the change in cluster size, we calculated the relative eastward and northward displacement from the cluster centroid at each time step over the course of a one-week period from 07 to 14 May. The effective diffusivity was then calculated directly from the first difference of the mean-squared displacement time series. The effective diffusivity was the bulk dispersion and includes the effects of turbulent diffusion and velocity shear. Drifters separated rapidly over the week as several were entrained in a southeasterly current while two moved coastward. The result of this spreading was an effective diffusion rate of $254 \mathrm{~m}^{2} \mathrm{~s}^{-1}$, within the broad ranges reported by [14], and likely reflects the action of velocity shear. The positive diffusion of the drifter cluster was not directly comparable to the satellite maps in Fig. 3, but it reinforced the view that oil spread rapidly over a large area around the Mississippi Delta and Gulf coast aided by winds and local currents.

\section{Transport Pathways: wind-driven coastal circulation}

Wind stress is particularly effective at generating strong coastal flows, and in regions of weak tidal currents, the wind-driven shelf currents may exert an important control on the transport and dispersion of pollutants such as oil. Spring and early summer winds in the NGOM are predominantly from the east-southeast. These winds produce northwest to north-northeastward surface Ekman drift. Strong easterly winds are therefore down-welling favorable along the NGOM coast and, when combined with buoyancy-driven flow from the Mississippi river plume, can produce a strong westward coastal current over large spans of the Louisiana and Texas shelf [15]. Spatial variation in the wind direction over the NGOM has been noted by [16].

Several episodes of sustained alongshore winds during June and July established a strong westward coastal flow on the NGOM shelf. Fig. 4a shows one such example in the combined trajectories of both FHD and Davis-style drifters between 30 June (green dots) and 14 July (red dots). Winds recorded at the NDBC 42040 moored buoy were sustained from the east-southeast during this time with average speed $>5 \mathrm{~ms}^{-1}$. Drifter trajectories over the entire region were generally westward and along shelf. Several drifters accelerated and made large along-shelf excursions. FHDs \#2533 and \#2528 located east and west of the Mississippi delta travelled $462 \mathrm{~km}$ and $370 \mathrm{~km}$, respectively, tracing a westward path roughly parallel to the Louisiana coast. FHD \#2533 briefly accelerated to speed $>1 \mathrm{~ms}^{-1}$ while passing southwest of the delta on 05 July.

During this period, a group of paired drifters were deployed along a line from northwest to southeast across the shelf and the slope. Each pair consisted of a single FHD (4.5m tether) and a Davis-style drifter from the Naval Oceanographic Office (NAVO). The drifter pairs were deployed within a few $\mathrm{km}$ and less than one hour apart on 03 July. The drift trajectories of each pair are shown in Fig. 4b. Several aspects of their subsequent drift are worth noting. Drifters deployed over the shelf $(<500 \mathrm{~m}$ depth), regardless of type, show a progressively westward and also on-shelf movement. The FHDs deployed near the shelf break (\#2572, \#2573, and \#2574) show rapid westnorthwest movement for several days after the 03 July deployment. The trajectories of the paired Davis-style drifters (\#2042551, \#20425543, and \#2042560) show the same general westward movement, but the drifters separated slowly by a few km per day. To examine this more closely, we briefly compared the relative response of these drifters to wind forcing from 04 to 09 July. The wind during this period was sustained in excess of $7 \mathrm{~ms}^{-1}$ from the east, with little directional variation. The comparative statistics are detailed in Table 1 but can be summarized in the following way. Of those drifters on the shelf $(<500 \mathrm{~m}$ depth), the Davis-style drifters moved more rapidly than FHDs by an average of $0.07 \mathrm{~ms}^{-1}$. Davis-style drifters traveled to the right of the wind by an average of $14.3^{\circ}$. By contrast, the FHDs drifted at an average of $29.5^{\circ}$ to the right of the wind. The greater cross-wind flow in the FHD trajectories was consistent with on-shelf Ekman transport under the influence of downwelling-favorable winds.

Farther offshore, drifters followed less uniform tracks. As can be seen in Fig. 4d, FHD \#2575 moved progressively onto the shelf to the northwest and cross-isobath, while the two most offshore drifters (FHD \#2576 and \#2577) meandered for several days before moving onto the shelf. The paired Davis-style drifters diverged rapidly from their counterparts and showed little agreement with FHD's in either speed or direction. The drifter pairs separated rapidly at $>10 \mathrm{~km} /$ day. The response of the off-shelf drifters was less obviously related to the along-shelf winds and included several episodes of upwind drift (not shown), resulting in large mean difference from the wind direction (FHDs \#2575-2577, Table 1). This apparent negative correlation was possibly a product of the very different water following capabilities of the different drifter designs [17]. It may also have resulted from progressive off-shelf variation in the mixed layer properties, spatial variability in the wind across the shelf, or "contamination" of wind-following behavior by counter currents associated with mesoscale eddies over the slope [11].

The NOAA NESDIS oil maps for the same period showed a net westward and along-shelf movement of oil over a wide range of longitudes from at least $94^{\circ} \mathrm{W}$ to $87^{\circ} \mathrm{W}$ (Fig. 4a). Large slicks located northeast of the Mississippi Delta and along the Gulf coast of LA/MS/AL on 30 June moved south and west by 10 July. The long trail of disaggregated slicks stretched along the inner Louisiana shelf as far as $93^{\circ} \mathrm{W}$. 


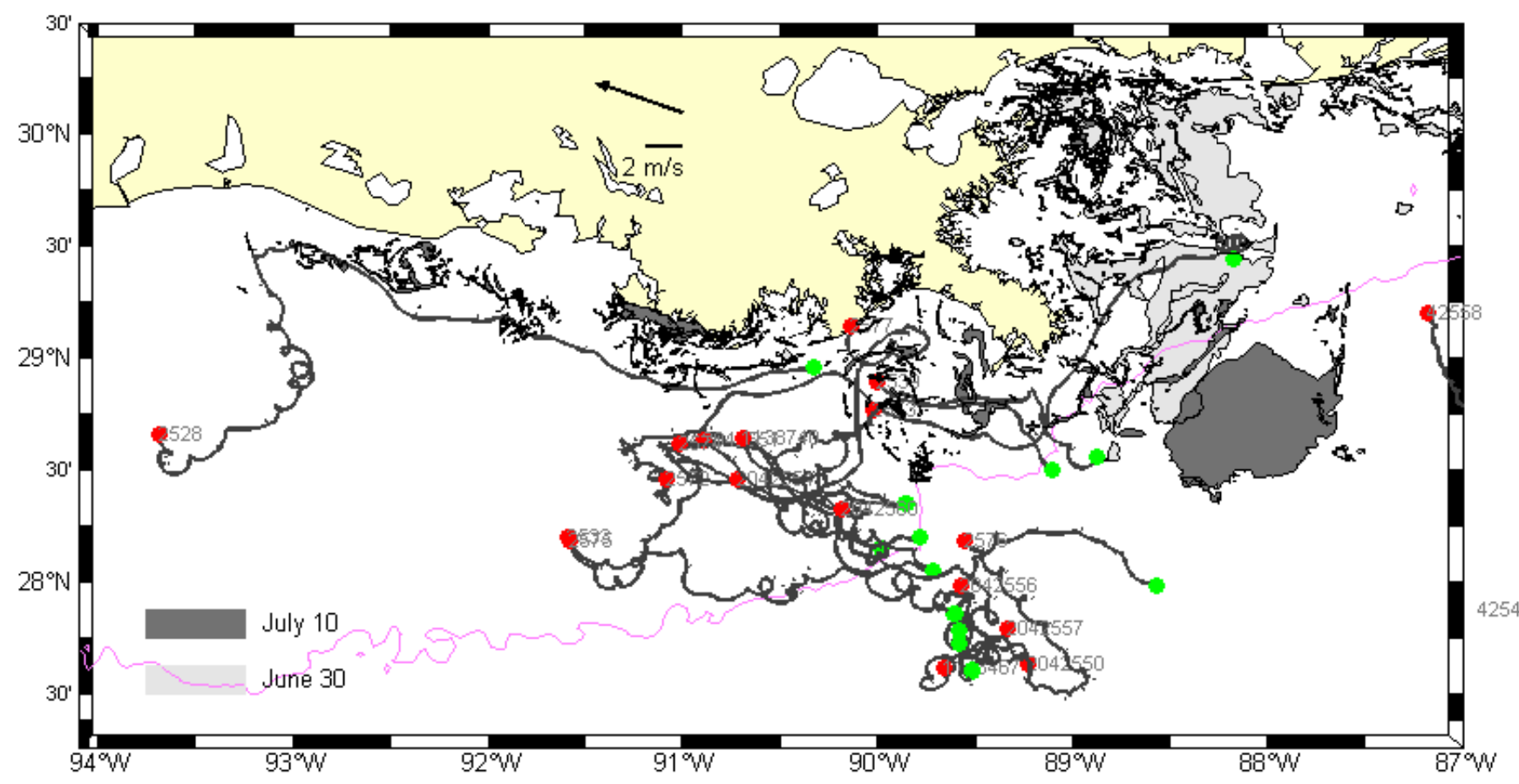

Figure 4a. FHD and NAVO Davis drifter trajectories from30 June (green dots) to 10 July (red dots) overlaid on NESDIS oil trajectory maps from 30 June and 10 July.

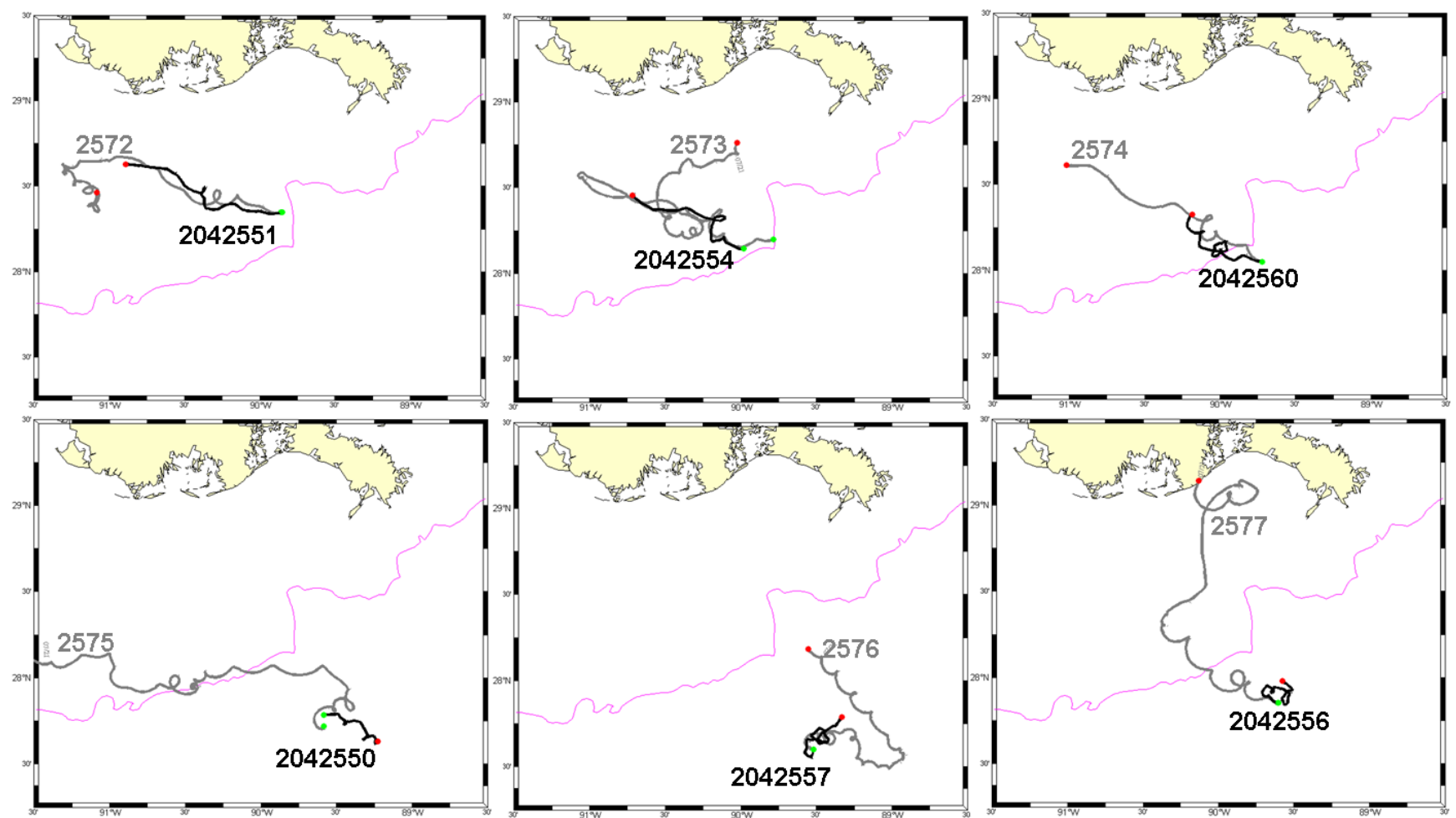

Figure 4b. Paired FHD (gray) and NAVO Davis drifter (black) trajectories from 03 to 10 July. 
TABLE I.

PAIRED FHD WITH 5 M TETHERS AND DAVIS-STYLE DRIFTERS RELEASED AT LOCATIONS ACROSS THE SHELF. STATISTICS ARE FOR 05-08 JULY DURING SUSTAINED ALONGSHELF WINDS. DRIFTERS ON THE SHELF ARE BOLDFACED. THE DATA ARE INTERPOLATED TO A COMMON TIME BASE AND LOW-PASS FILTERED TO RESOLVE THE SUB-INERTIAL VARIABILITY. THE MEAN DIRECTIONAL DIFFERENCE $\left(\overline{\theta_{w}-\theta_{d}}\right)$ AND ROOT MEAN SQUARE OF $\left(\overline{\theta_{w}-\theta_{d}}\right)$ OF THE WIND DRIFTER DIRECTION ARE CALCULATED WITH (+) INDICATING DRIFT TO THE RIGHT AND (-) TO THE LEFT. FOR SPEED DIFFERENCES $\Delta|V|$ A NEGATIVE SIGN INDICATES FASTER DAVIS-STYLE DRIFTERS RELATIVE TO THE PAIRED FHD.

\begin{tabular}{|c|c|c|c|c|c|c|c|c|}
\hline \multicolumn{3}{|c|}{${\text { July } 4-9 \text { Wind }_{\mathrm{ave}}=7.2 \mathrm{~ms}^{-1}}_{\bar{\theta}}=286^{\circ}$} & \multicolumn{4}{c|}{ July 4-9 Wind $_{\mathrm{ave}}=7.2 \mathrm{~ms}^{-1} \bar{\theta}=286^{\circ}$} \\
\hline ID \# & $\left(\overline{\theta_{w}-\theta_{d}}\right)$ & Sense & $R M S(\Delta \theta)$ & $|\overline{\Delta V}|$ & ID \# & $\left(\overline{\theta_{w}-\theta_{d}}\right)$ & Sense & $R M S(\Delta \theta)$ \\
\hline $\mathbf{2 5 7 2}$ & 18.9 & $(+)$ & 23.4 & -0.09 & $\mathbf{2 0 4 2 5 5 1}$ & 5.8 & $(+)$ & 18.6 \\
\hline $\mathbf{2 5 7 3}$ & 37.7 & $(+)$ & 22.4 & -0.04 & $\mathbf{2 0 4 2 5 5 4}$ & 12.35 & $(+)$ & 21.4 \\
\hline $\mathbf{2 5 7 4}$ & 32.0 & $(+)$ & 25.4 & -0.09 & $\mathbf{2 0 4 2 5 6 0}$ & 24.8 & $(+)$ & 15.9 \\
\hline 2575 & 64.0 & $(+)$ & 43.5 & -0.13 & 2042550 & 35.9 & $(+)$ & 17.8 \\
\hline 2576 & 128.6 & $(+)$ & 157.6 & -0.13 & 2042557 & 23.2 & $(+)$ & 6.7 \\
\hline 2577 & 67.2 & $(+)$ & 55.3 & 0.33 & 2042556 & 182.5 & $(+)$ & 121.9 \\
\hline
\end{tabular}

\section{Transport Pathways: Loop Current entrainment}

The offshore circulation in the GOM is dominated by the Loop Current and associated mesoscale eddies. Given the Macondo well site location on the NGOM slope, a prolonged spill beyond several weeks elevated the threat of entrainment of oil into the Loop Current and subsequently extensive spreading to the interior Gulf, the West Florida Shelf, and the Straits of Florida. In two separate episodes in May and June, satellite observations indicated the offshore extension of the oil patch. We present evidence of episodic export pathways between the main spill site and distant regions of the Gulf of Mexico and their relation to the offshore oceanic mesoscale circulation.

During the 15 May to 01 June time period, FHD \#2521 ( $45 \mathrm{~m}$ tether) was deployed to the southwest of the spill site one day after the Deepwater Horizon explosion (Fig. 5). The Loop Current was in a mature phase at the time, having pushed north into the Gulf (north of $27.5^{\circ} \mathrm{N}$ ) and over the northern Gulf slope. Relatively light winds (averaging $<5$ $\mathrm{ms}^{-1}$ ) prevailed during this period. To the south and west of the Mississippi Delta region, a weak anticyclonic eddy (ACE) was present, possibly a result of a recent peak in freshwater influx from the Mississippi River that peaks in mid April [18]. A large cyclonic frontal eddy (CE) was present just north of the main Loop Current front and, together with the ACE to the west, created a region of accelerated flow to the southwest from a latitude as far north as $28.5^{\circ} \mathrm{N}$ (just south of the Macondo well site). The counter-rotating eddy circulation resulted in the entrainment of FHD \#2521 into the northern edge of the Loop Current. Velocities $>1.0 \mathrm{~ms}^{-1}$ were sustained from 18 to 21 May when the drifter re-circulated around the large $\mathrm{CE}$ to the north of the front (not shown). Satellite-derived maps of surface oil distribution from NOAA NESDIS indicated the progressive entrainment of surface oil in the same direction over similar time scales.

Subsequent deployment of drifters suggested that entrainment and export pathways from the well site were reestablished episodically. As evidence we show a group of FHDs with $45 \mathrm{~m}$ tethers deployed west to east with $\sim 50 \mathrm{~km}$ separation (FHD \#s 2564, 2565, 2561, and 2562). The locations were directly south of the Macondo site and within high concentrations of oil as indicated by NOAA NESDIS map at the time (Fig. $6 \& 7$ ). The offshore circulation was again dominated by the influence of closely spaced counterrotating mesoscale eddies: the anticyclonic Loop Current eddy centered at $25.17^{\circ} \mathrm{N}, 86.92^{\circ} \mathrm{W}$ and a large elliptical CE to the southeast centered at $26.75^{\circ} \mathrm{N}, 85.83^{\circ} \mathrm{W}$ over the slope of the West Florida Shelf. The drifters were deployed into the region where the combined flow resulting from their conjunction created a potential pathway for rapid entrainment. Several significant features were notable in the drift trajectories. Beginning on 13 June, the flow near the initial deployment locations was evidently dominated by weak inertial oscillations superimposed on a weak background flow that varied in direction from west to east. FHDs \#2564 and \#2565 moved south or south-southeast, while FHDs \#2561 and \#2562 located 48 and $96 \mathrm{~km}$ to the east, respectively, meandered slowly to the south-southwest. By 19 June, however, all drifters migrated to the east and southeast, clearly entrained by currents arising from the nearby eddies. Although these drifters were deployed within several hours of one another, the spatial variation in flow caused progressive separation at $\sim 10 \mathrm{~km} /$ day, leading to the temporal dispersion of the drifter group as they entered the high velocity region. The region of strongest surface velocity (and velocity gradient) was at the confluence of the two eddies. 


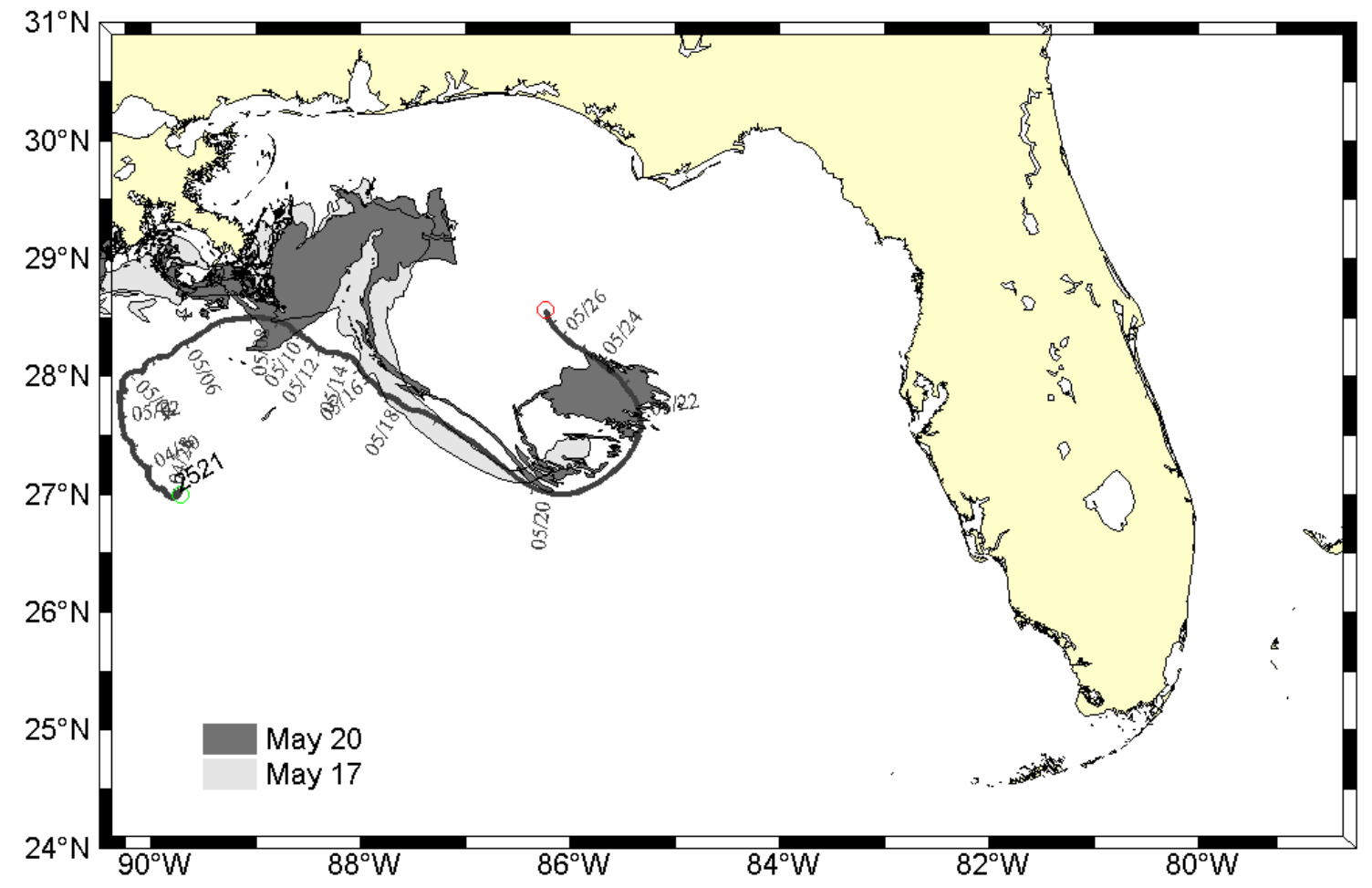

Figure 5. Trajectory of FHD \#2521 overlaid on NESDIS oil distribution maps from 17 May and 20 May.

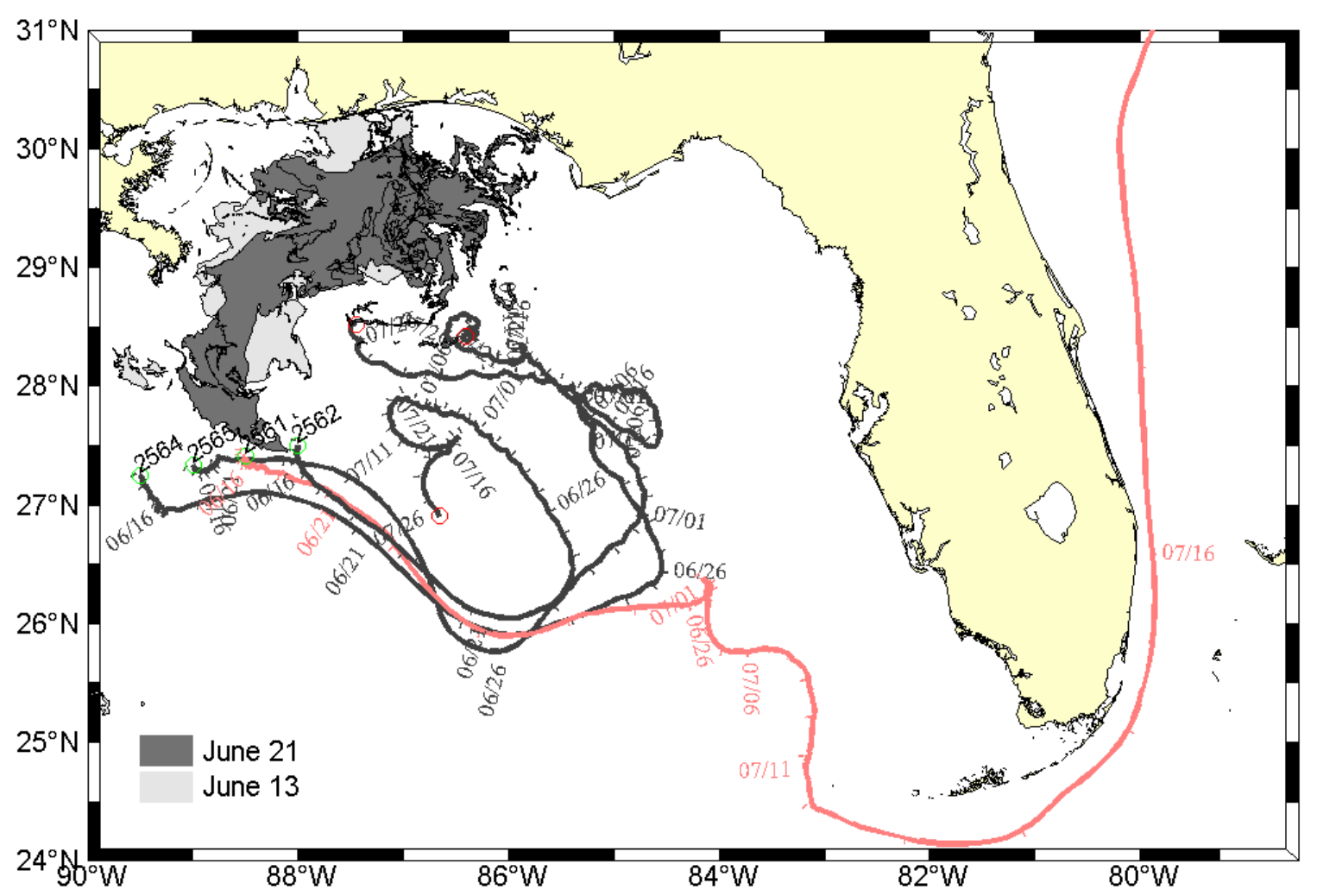

Figure 6. Trajectories of the drifter group \#'s 2561, 2562, 2564, and 2565 from 13 June overlaid on. oil distribution maps from NOAA NESDIS for 13 June and 21 June. 


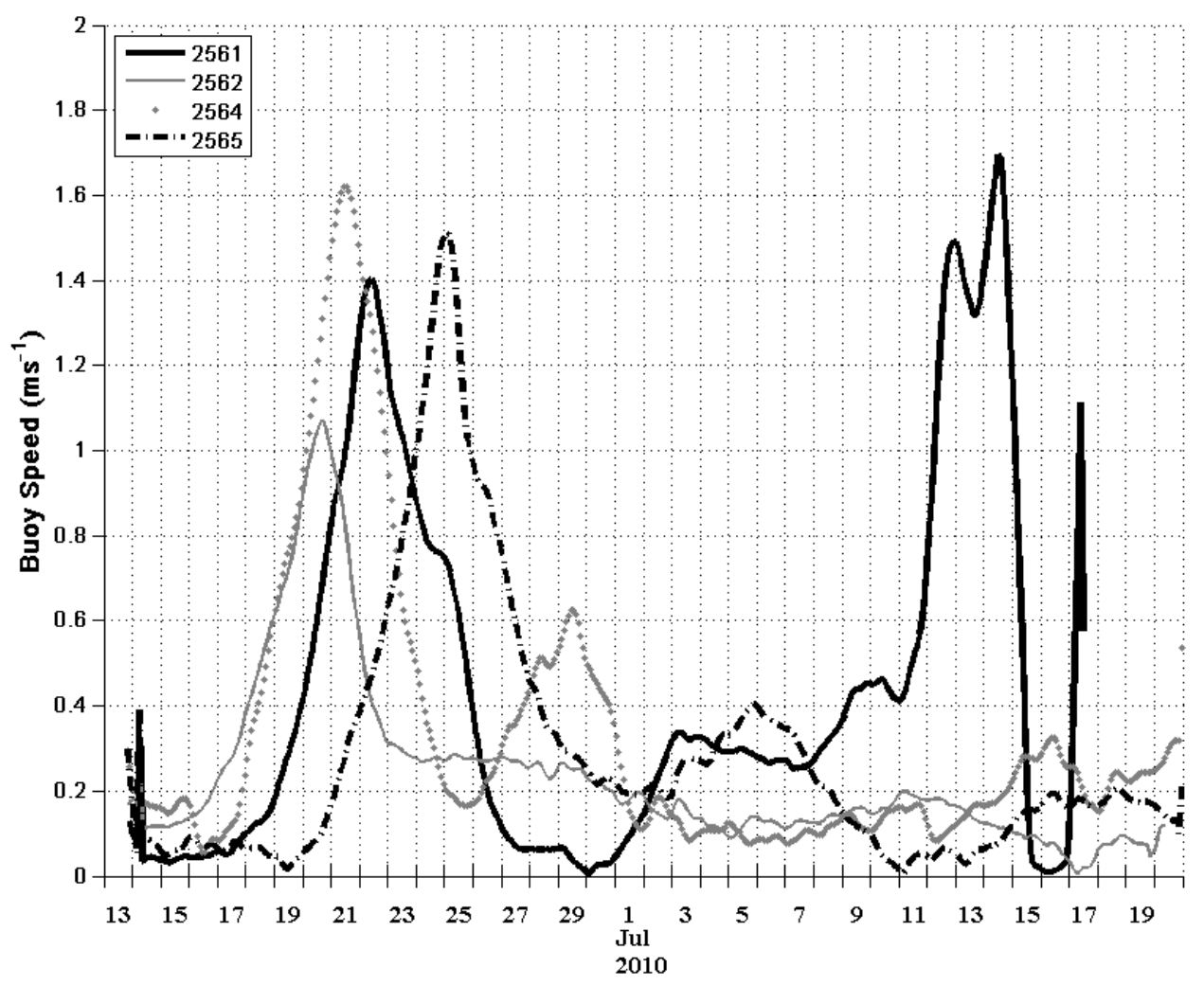

Figure 7. Along-track speeds of FHDs \#2561, \#2562, \#2564, and \#2565.

FHDs \#2562 and \#2564 accelerated to $>1 \mathrm{~ms}^{-1}$ in the juncture region as early as 20 June although they were deployed approximately $140 \mathrm{~km}$ apart at the east and west end of the drifter group, respectively. FHD \#2561 entered the same region (speeds $>1 \mathrm{~ms}^{-1}$ ) a day later (22 June) while FHD \#2565 lagged behind and transited nearly the same region on 25 June. Passing between the two eddies over a 5-day time span, the trajectories converged in space so that each drifter was funneled one after the other through a narrow region less than $19 \mathrm{~km}$ wide located at $26.3^{\circ} \mathrm{N}$, $86.7^{\circ} \mathrm{W}$. Leaving this narrow confluence, the drifters experienced a general counter clockwise motion around the CE to the north. FHDs \#2564, \#2562, and \#2565 were swept around the CE and by 21 July were distributed north of $27.5^{\circ} \mathrm{N}$ and west of $86^{\circ} \mathrm{W}$. FHD $\# 2561$, on the other hand, entered the confluence region a day behind the first two drifters and three days ahead of the fourth drifter but did not recirculate around the CE. Instead it was expelled to the east over the West Florida Shelf and drifted slowly south until it became entrained by the Loop Current and exited from the Gulf by 14 July.

Overlays of NOAA NESDIS oil maps several days apart indicate the broad influence exerted by the eddies on the surrounding circulation over the slope and near the Macondo site. Oil slicks were advected east-southeastward along the northern edge of the Loop Current.

\section{SUMMARY AND CONCLUSIONS}

Monitoring of oil dispersion and transport throughout the shelf, slope, and deepwater regions of the Gulf of Mexico represents a significant challenge. The case discussed here is unique because of the spill's prolonged duration and magnitude, its location on the continental slope, and the extensive impact on coastal and oceanic regions. As an added complication, the spill occurred in part of the open ocean subjected to strong and highly variable currents capable of transporting oil to remote locations. Furthermore, dispersant applied to the oil resulted in large quantities of oil spreading throughout the mixed layer and within the water column.

Acquiring rapid, accurate, and usably synoptic maps of circulation was critical to forecasting oil movement, fate, and landfall. Drifter observations were crucial for validating satellite images showing connectivity between the shelf and the Loop Current (and associated eddies), for identifying zones of convergence, and revealing active transport pathways between the oil spill and other locations within the Gulf and beyond.

In this paper, we have described the use of an airdeployed satellite-tracked drifter to trace the Lagrangian circulation in the GOM. Although several drifter types were available for use in the spill response, the use of a parachute shaped drogue design provided a significant 
practical advantage through its dual use in an airdeployment system. Such an air-launched drifter can be deployed rapidly over large areas.

Several major transport pathways were evident in these drifter data, resulting from physical mechanisms operating over different scales (in time and in space). It has been long recognized that periods of prevailing along-shore wind can generate strong shelf-trapped coastal flows along the NGOM shelf. A few days of strong winds during early July resulted in a shelf-wide coherent response of drifters combined with concurrent along-shelf dispersion of satellite-measured oil distributions over hundred of $\mathrm{km}$. Current-following drifters clearly revealed the resulting alongshore flow and also the existence of cross-shelf (and cross-wind) flow. Such observations are important since cross-shelf exchange of water may have occurred with important consequences for oil transport.

The value of a wide-spread network of Lagrangian drifters to future oil spill responses in this region is clearly in the ability to discover and trace the circulation features that result in along-shelf and off-slope entrainment of oil particles and their export from the Gulf of Mexico. The offshore circulation in the Gufl of Mexico is dominated by the Loop Current and associated mesoscale eddies. In two separate episodes in May and June drifter observations showed the extensive spreading and entrainment of surface oil into the Loop Current. We also observed evidence of active export pathways between the main spill site and distant regions of the Gulf of Mexico. These events were clearly instigated by the incursions of a mature Loop Current and its associated eddy field towards the NGOM slope and in close proximity to the Macondo site. Although the entrainment of FHD \#2561 into the Loop Current and it's subsequent trajectory indicated an alarming potential for direct oil transport to the West Florida shelf, to our knowledge, with the exception of the extreme northwestern coast of Florida, oil slicks are yet to be sighted on this part of the shelf. These results do suggest, however, that the direct pathways between the Macondo site, the West Florida Shelf, and beyond are "open" from time to time and able to transport oil to these locations given enough time.

\section{ACKNOWLEDGMENT}

The authors would like to thank James W. Feeney and Patrice D. Coholan for allowing the use of Horizon Marine's data in this study. We would also like to acknowledge the use of NOAA NESDIS oil trajectory maps (http://www.ssd.noaa.gov/PS/MPS/deepwater.html). thank Glenn Watabyashi from NOAA ORR and Frank Bub from the Naval Oceanographic Office for their cooperation and providing access to buoy data.

\section{REFERENCES}

[1] T.C. Royer, J.A. Vermersch, T.J. Weingartner, H.J. Niebauer, and R.D. Muench, "Ocean Circulation Influencing the Exxon Valdez oil spill," Oceanography, 1990.

[2] G.J. McNally, and W.B White, "Wind-driven flow in the mixed layer observed by drifting buoys during autumn-winter in midlatitude North Pacific," J. Phys. Oceanogr., vol. 15, pp. 684-694, 1985.

[3] R.J. Fiocco and A. Lewis, "Oil spill dispersants," Pure Appl. Chem., 1999, vol. 71, no. 1, pp. 27-42.

[4] A. Lewis, P.S. Dalin, T. Strom-Kristiansen, A.B. Nordvik, and R.J. Fiocco, "Weather and chemical dispersion of oil at sea," International Oil Spill Conference, 2009.

[5] R. Varadaraj, M.L. Robbins, J. Bock, S. Pace, and D. MacDonald, "Dispersion and biodegradation of oil spills on water," International Oil Spill Conference, 2009.

[6] R. P.J. Swannell and F. Daniel, "Effect of dispersants on oil biodegradation under simulated marine conditions," International Oil Spill Conference, 1999, \#212.

[7] A. Reisfeld, E. Rosenberg, and D. Gutnick, "Microbial degradation of crude oil: factors affecting the dispersion in sea water by mixed and pure cultures," Appl. Microbiol., 1972, vol. 24, no. 3, pp. 363-368.

[8] O.M. Aamo and H. Jensen, "Operational use of ocean surface drifters for tracking spilled oil," Proceedings of the 20th Arctic and Marine Oil Spill Program (AMOP) Technical Seminar, Vancouver, Canada, 1997.E. Garcia-Ladona et al., "The use of surface drifting floats in the monitoring of oil spills. The Prestige case," International Oil Spill Conference, 2005

[9] J.M. Price et al., "Evaluation of an oil spill trajectory model using satellite-tracked, oil-spill-simulating drifters," MMS, 0-933957-31-9.

[10] R.H. Goodman, D. Simecek-Beatty, and D. Hodgins, "Tracking buoys for oil spills," International Oil Spill Conference, 2009.

[11] P. Hamilton, "Eddy statistics from Lagrangian drifters and hydrography for the northern Gulf of Mexico slope," J. Geophy. Res., 2007, vol. 112, C09002, doi:10.1029/2006JC003988.

[12] A.L. Sybrandy and P.P Niiler, "The WOVE/TOGA SVP Lagrangian Drifter Construction manual," Scripps Institute of Oceanography, Univ of Cal. San Diego, 1990, SIO Refernce, pp. 90-248.

[13] NOAA Atlantic and Meteorological Laboratory and NOAA Southeast Fisheries Science Center, NOAA AOML/SEFSC Workshop on Deepwater Horizon oil spill efforts, 1-2 July, 2010, Miami, FL.

[14] J. Manning, and J. Curchill, "Estimates of dispersion from clustereddrifter deployments on the southern flank of Georges bank," DeepSea Research II, 2006, doi:10.1016/j.dsr2.2006.08.004.

[15] Cochrane and Kelly, "Low frequency circulation on the TexasLouisiana continental shelf," J. Geophy. Res., 1986, 91(C9), pp. 10645-10659.

[16] G. Gutierrez de Velasco and C.D. Winant, "Seasonal patterns of wind stress curl over the Gulf of Mexico," J. Geophy. Res., 1996, vol. 101, pp. $18127-18140$.

[17] P.P. Niiler and J.D. Paduan, "Wind-driven motions in the Northeast Pacific as measured by Lagrangian drifters," J. Phys. Oceanogr., 1995, vol. 25, pp. 2819-2830.

[18] N.D. Walker, "Satellite assessment of Mississippi River plume variability: causes and predictability," Remote Sens. Environ., 1996, vol. 58 , no. 1 , pp. 21-35. 